Article

\title{
Bis(formylphenolato)cobalt(II)-Mediated Alternating Radical Copolymerization of tert-Butyl 2-Trifluoromethylacrylate with Vinyl Acetate
}

\author{
Sanjib Banerjee ${ }^{1,+}$ (D) , Ekaterina V. Bellan ${ }^{2}$, Florence Gayet ${ }^{2}$, Antoine Debuigne ${ }^{3}$, \\ Christophe Detrembleur ${ }^{3}$, Rinaldo Poli ${ }^{2,4, *}$ (D), Bruno Améduri ${ }^{1}$ (D) and Vincent Ladmiral ${ }^{1, *}$ \\ 1 Institut Charles Gerhardt Montpellier, University of Montpellier, CNRS, ENSCM, Place Eugène Bataillon, \\ 34095 Montpellier CEDEX 5, France; sanjib.banerjee@iitbhilai.ac.in (S.B.); bruno.ameduri@enscm.fr (B.A.) \\ 2 Laboratoire de Chimie de Coordination (LCC), Université de Toulouse, CNRS, UPS, INPT, \\ 205 route de Narbonne, BP 44099, 31077 Toulouse CEDEX 4, France; ekaterina.bellan@gmail.com (E.V.B.); \\ florence.gayet@lcc-toulouse.fr (F.G.) \\ 3 Center for Education and Research on Macromolecules (CERM), University of Liege, CESAM Research Unit, \\ Sart-Tilman B6a, 4000 Liege, Belgium; adebuigne@ulg.ac.be (A.D.); christophe.detrembleur@ulg.ac.be (C.D.) \\ 4 Institut Universitaire de France, 1, rue Descartes, 75231 Paris CEDEX 05, France \\ * Correspondence: rinaldo.poli@lcc-toulouse.fr (R.P.); vincent.ladmiral@enscm.fr (V.L.) \\ + Present address: Department of Chemistry, Indian Institute of Technology Bhilai, GEC Campus, Sejbahar, \\ Raipur 492015, Chhattisgarh, India.
}

Received: 7 November 2017; Accepted: 7 December 2017; Published: 12 December 2017

\begin{abstract}
The organometallic-mediated radical polymerization (OMRP) of vinyl acetate (VAc) and its OMR copolymerization (OMRcoP) with tert-butyl 2-trifluoromethylacrylate (MAF-TBE) mediated by $\mathrm{Co}(\mathrm{SAL})_{2}(\mathrm{SAL}=2$-formylphenolato or deprotonated salicylaldehyde) produced relatively well-defined PVAc and poly(VAc-alt-MAF-TBE) copolymers at moderate temperature $\left(<40{ }^{\circ} \mathrm{C}\right)$ in bulk. The resulting alternating copolymer was characterized by ${ }^{1} \mathrm{H}-,{ }^{13} \mathrm{C}$ - and ${ }^{19} \mathrm{~F}$-nuclear magnetic resonance (NMR) spectroscopies, and by size exclusion chromatography. The linear first-order kinetic plot, the linear evolutions of the molar mass with total monomer conversion, and the relatively low dispersity $(\nexists \sim 1.55)$ of the resulting copolymers suggest that this cobalt complex provides some degree of control over the copolymerization of VAc and MAF-TBE. Compared to the previously investigated cobalt complex OMRP mediators having a fully oxygen-based first coordination sphere, this study emphasizes a few peculiarities of $\mathrm{Co}(\mathrm{SAL})_{2}$ : a lower ability to trap radical chains as compared to $\mathrm{Co}(\mathrm{acac})_{2}$ and the absence of catalytic chain transfer reactions, which dominates polymerizations carried in the presence of 9-oxyphenalenone cobalt derivative.
\end{abstract}

Keywords: alternating copolymers; cobalt complex; fluoropolymer; organometallic mediated radical polymerization; poly(vinyl acetate)

\section{Introduction}

Fluoropolymers are unique materials, exhibiting outstanding properties, suitable for high-value added applications [1,2]. The incorporation of sequences of these polymers into a di- or multi-block [3] polymer architectures could lead to interesting materials of even greater value. Extensive research and development of different reversible deactivation radical polymerization (RDRP) techniques over the last two decades has enabled the facile synthesis of macromolecules with a high degree of complexity and well-defined architectures [4,5]. Although nitroxide-mediated radical polymerization (NMP) [6], atom transfer radical polymerization (ATRP) [7], iodine-transfer polymerization (ITP) [8-10] and reversible addition-fragmentation chain transfer (RAFT) polymerization [11-15] have been comparatively more studied, organometallic-mediated radical polymerization (OMRP) [16-20] has 
recently emerged as a potent RDRP technique for the polymerization of "less activated monomers" (LAMs), such as vinyl imidazolium salts [21,22] or vinyl amides (such as vinyl pyrrolidone) [23]. Indeed, for these more difficult monomers, OMRP and, in particular, cobalt-mediated radical polymerization (CMRP) [24] has proven very efficient, opening synthetic routes for homopolymers and block copolymers that could only be prepared with a lower level of control or not at all by other RDRP techniques. The technique was pioneered by Wayland et al. [25] using tetramesitylporphyrin for the controlled polymerization of acrylates, and since then several other $\mathrm{Co}^{\mathrm{II}}$ complexes with different donor atom combinations and coordination geometries have been reported. However, the controlled polymerization of LAMs seems so far restricted to complexes supported by chelating oxygen-based ligands, like the archetypic bis(acetylacetonate)cobalt(II) complex, $\mathrm{Co}(\mathrm{acac})_{2}$ (1a), first introduced by Debuigne et al. [26] for the controlled polymerization of vinyl acetate (VAc). To the best of our knowledge, investigations of other $\mathrm{Co}^{\mathrm{II}}$ complexes entirely supported by oxygen atoms in OMRP has, so far, been limited to the 1,1,1-trifluoro- and 1,1,1,5,5,5-hexafluoropentan-2,4-dionates (1b and 1c) [27], to the 2,2,6,6-tetramethylheptan-3,5-dionate (1d) [28] and to the 9-oxyphenalenone derivative (2) [29] (Scheme 1).<smiles>[R]C1=COC2(C=C([R])C=C([R])O2)OC([R])=C1</smiles>

1

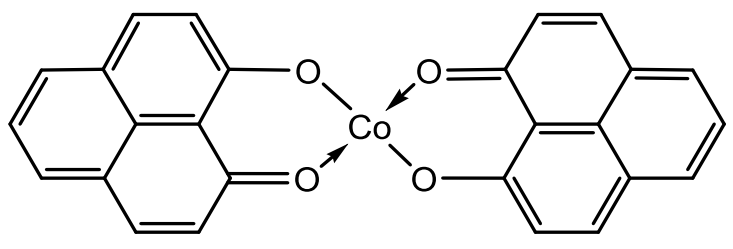

2

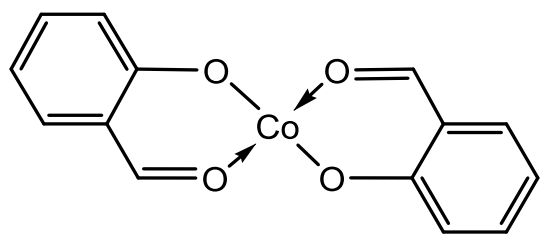

3

Scheme 1. Schematic representations of the cobalt(II) complexes: bis(acetylacetonato)cobalt(II) (1a); bis (1,1,1-trifluoro-acetylacetonato)cobalt(II) (1b); bis(1,1,1,5,5,5-hexafluoropentan-2,4-dionato)-cobalt(II) (1c); bis(2,2,6,6-tetramethylheptan-3,5-dionato)cobalt(II) (1d); bis(9-oxyphenalenonato)-cobalt(II) (2), and; bis(2-formylphenolato)cobalt(II) (3).

We are interested in expanding the available array of cobalt(II) complexes as OMRP mediators and to understand how the metal coordination sphere affects the metal controlling ability, potentially providing access to the controlled polymerization of new challenging monomers such as the fluorinated olefins [30,31]. The focus of the present article is the assessment, for the first time, of the air-stable bis(2-formylphenolato)cobalt(II) complex $\left(\mathrm{Co}(\mathrm{SAL})_{2}, 3\right.$, Scheme 1), where the 2-formylphenolate is the deprotonated form of salicylaldehyde. This complex has already been described in the literature $[32,33]$ and is quite easily synthesized. Its performances in the bulk polymerization of VAc and in the bulk copolymerization of VAc and tert-butyl 2-trifluoromethylacrylate (MAF-TBE) are evaluated here. The combination of these two monomers was recently shown to radically polymerize in a strictly alternating fashion (their reactivity ratios are essentially zero) [34] and to be well controlled by $\mathrm{Co}(\mathrm{acac})_{2}$ [35]. Fluorinated copolymers containing 2-(trifluoromethyl)acrylic acid (MAF) and alkyl 2-trifluoromethacrylates (MAF-esters) may have applications in molecularly imprinted polymers, microlithography, polymer gel electrolyte membranes for fuel cells, and polymer electrolytes for Li-ion batteries [36]. Such copolymers may also contribute to the development of new materials with enhanced properties (e.g., high hydrophobicity, adhesion) [37-39] for high-tech applications (e.g., functional coatings or membranes). 


\section{Materials and Methods}

\subsection{Materials}

Vinyl acetate (VAc, $\geq 99 \%$, Sigma-Aldrich Chimie, Saint Quentin-Fallavier, France) and tert-butyl 2-trifluoromethylacrylate (MAF-TBE, kindly donated by Tosoh F-Tech Company, Shunan, Japan) were stored under nitrogen and purged for $30 \mathrm{~min}$ with nitrogen before use. 2,2,6,6-Tetramethyl-1piperidinyloxy (TEMPO) (Acros Organics, Geel, Belgium), mesitylene (Mes) (>99.9\%, Sigma-Aldrich Chimie, Saint Quentin-Fallavier, France), and 2,2'-azobis(4-methoxy-2,4-dimethylvaleronitrile) (V-70, Wako chemicals, Neuss, Germany) were used as received. Acetone and laboratory reagent grade pentane (purity $>95 \%$ ) were purchased from Sigma-Aldrich and used as received. The deuterated solvents used for nuclear magnetic resonance (NMR) spectroscopy THF- $d_{8}$, acetone- $d_{6}$ and $\mathrm{CDCl}_{3}$ were purchased from Euroiso-top (Grenoble, France) (purity $>99.8 \%$ ). The cobalt complex 3 was prepared according to the published procedure [32,33].

\subsection{Experimental Procedures}

\subsubsection{OMRP of VAc Initiated by V-70 in the Presence of 3}

All manipulations were carried out under a protective argon atmosphere. Compound 3 $(0.087 \mathrm{mmol}, 0.026 \mathrm{~g})$ and V70 $(0.174 \mathrm{mmol}, 0.054 \mathrm{~g})$ were introduced into the Schlenk tube and purged by three vacuum-argon cycles, followed by the addition of degassed vinyl acetate $(4 \mathrm{~mL}, 43.4 \mathrm{mmol})$ and $0.2 \mathrm{~mL}$ of mesitylene. The reaction mixture was degassed by two freeze/pump/thaw cycles. Then, V-70 was added to the reaction mixture and the Schlenk tube was immersed in an oil bath at $30{ }^{\circ} \mathrm{C}$ under magnetic stirring. Aliquots were withdrawn periodically to monitor the reaction progress by ${ }^{1} \mathrm{H}-\mathrm{NMR}$ and size exclusion chromatography (SEC). The monomer conversion was determined by ${ }^{1} \mathrm{H}-\mathrm{NMR}$ spectroscopy in THF- $d_{8}$ using mesitylene as an internal standard. The samples for SEC characterization were quenched with excess TEMPO, then precipitated from pentane and dried under vacuum. The VAc conversion was calculated using Equation (1) or (2) where $\int_{i}^{j} \mathrm{CH}$ stands for the integral of the $\mathrm{CH}$ signal ranging from $\mathrm{i}$ ppm to $\mathrm{j}$ ppm in the ${ }^{1} \mathrm{H}-\mathrm{NMR}$ spectrum at time $t$ (unless stated otherwise).

$$
\begin{gathered}
\text { \%VAc conversion }=\frac{\left(\int_{4.75}^{5.20} \mathrm{CH}-\int_{4.35}^{4.65} \mathrm{CH}\right)}{\int_{4.75}^{5.20} \mathrm{CH}} \times 100 \\
\% \text { VAc conversion }=\frac{\left[\int_{7.10}^{7.40} \mathrm{CH}(\mathrm{VAc}) / \int_{6.60}^{6.90} \mathrm{CH}(\text { mesitylene })\right]}{\left[\int_{7.10}^{7.40} \mathrm{CH}(\mathrm{VAc}) / \int_{6.60}^{6.90} \mathrm{CH}(\text { mesitylene })\right]_{\mathrm{t}=0}} \times 100
\end{gathered}
$$

\subsection{2. $\mathrm{Co}(\mathrm{SAL})_{2}-\mathrm{Mediated}$ Radical Copolymerization of VAc and MAF-TBE}

All copolymerizations were performed under a dry dinitrogen atmosphere using Schlenk techniques. In a typical copolymerization, V-70 $(278 \mathrm{mg}, 0.9 \mathrm{mmol})$ and $3(54 \mathrm{mg}, 0.3 \mathrm{mmol})$ were placed into a Schlenk flask and purged by three vacuum-nitrogen cycles. Then, the degassed monomers, VAc $(7.4 \mathrm{~mL}, 80.5 \mathrm{mmol})$ and MAF-TBE $(14.1 \mathrm{~mL}, 80.5 \mathrm{mmol})$ were introduced into the flask under a nitrogen flux and the reaction mixture was heated at $40{ }^{\circ} \mathrm{C}$ under magnetic stirring. During polymerization, samples were withdrawn from the reaction medium at regular intervals to monitor the monomer conversions by ${ }^{1} \mathrm{H}-\mathrm{NMR}$ spectroscopy (for VAc) and ${ }^{19} \mathrm{~F}-\mathrm{NMR}$ spectroscopy (for MAF-TBE), and for polymer molar masses and dispersities $(\bigoplus)$ determinations using SEC (see SI, Table S2, Figures S1 and S2). All the samples were quenched with an excess of TEMPO (solution in degassed $\mathrm{THF}$, typically 6 equivalents with respect to the number of moles of $\mathbf{3}$ used in the copolymerization) to remove the residual cobalt complex from the polymer chain-end before the SEC analysis. The monomer conversions were determined by ${ }^{1} \mathrm{H}-\mathrm{NMR}$ (for VAc) and ${ }^{19} \mathrm{~F}-\mathrm{NMR}$ (for MAF-TBE) spectroscopies using Equations (3) and (4), respectively, where $\int_{i}^{\mathrm{j}} \mathrm{CH}$ and $\int_{n}^{\mathrm{m}} \mathrm{CF}_{3}$ stand for the integral of the $\mathrm{CH}$ 
signal, ranging from i ppm to $\mathrm{j} p \mathrm{pm}$ in the ${ }^{1} \mathrm{H}-\mathrm{NMR}$ spectrum at time $t$, and that of the $\mathrm{CF}_{3}$ signal, ranging from $n$ ppm to $m$ ppm in the ${ }^{19} \mathrm{~F}-\mathrm{NMR}$ spectrum at time $t$.

$$
\begin{gathered}
\text { \%VAc conversion }=\frac{\int_{5.00}^{5.40} \mathrm{CH}}{\left(\int_{4.35}^{4.65} \mathrm{CH}+\int_{5.00}^{5.40} \mathrm{CH}\right)} \times 100 \\
\% \mathrm{MAF}-\mathrm{TBE} \text { conversion }=\frac{\int_{-68.5}^{-70.5} \mathrm{CF}_{3}}{\int_{-66.5}^{-67.5} \mathrm{CF}_{3}+\int_{-68.5}^{-70.5} \mathrm{CF}_{3}} \times 100
\end{gathered}
$$

After completion of the reaction, the unreacted monomers were removed under vacuum. The remaining crude product was dissolved in acetone and precipitated twice from chilled pentane. It was then filtered through a filter funnel, and dried under vacuum $\left(10^{-3} \mathrm{bar}, 40^{\circ} \mathrm{C}\right)$ for $12 \mathrm{~h}$. The purified copolymers were characterized by ${ }^{1} \mathrm{H}-,{ }^{19} \mathrm{~F}$ - and ${ }^{13} \mathrm{C}-\mathrm{NMR}$ spectroscopies (see Supporting Information, Figures S3-S5) and by SEC (see Section 3).

\subsection{Characterizations}

\subsubsection{Size Exclusion Chromatography (SEC)}

The molar masses $\left(M_{n} \mathrm{~s}\right)$ and dispersities $(\bigoplus \mathrm{s})$ of the polymers were assessed by size exclusion chromatography (SEC). The SEC system (Agilent Technologies, Les Ulis, France) used for the poly(VAc-alt-MAF-TBE) copolymer analysis was equipped with a PL0390-0605390 LC light scattering detector functioning at two diffusion angles $\left(15^{\circ}\right.$ and $\left.90^{\circ}\right)$, a PL0390-06034 capillary viscometer, and a 390-LC PL0390-0601 refractive index detector and two PL1113-6300 ResiPore $300 \times 7.5 \mathrm{~mm}$ columns. The entire SEC system was equilibrated at $35^{\circ} \mathrm{C}$. DMF (containing $0.1 \mathrm{wt} \%$ of $\mathrm{LiCl}$ ), at a flow rate of $0.8 \mathrm{~mL} \mathrm{~min}{ }^{-1}$ was used as the eluent, while toluene was used as the flow rate marker. Poly(methyl methacrylate) standards were used for calibration and typical sample concentration employed was $10 \mathrm{mg} \mathrm{mL}^{-1}$. The results were processed using the corresponding Agilent software. The SEC analyses of the poly(vinyl acetate) samples were carried out in filtered THF (flow rate: $1 \mathrm{~mL} \mathrm{~min}{ }^{-1}$ ) at $35^{\circ} \mathrm{C}$ on a $300 \times 7.5 \mathrm{~mm}$ PL gel $5 \mu \mathrm{m}$ mixed-D column (Polymer laboratories) equipped with multi-angle light-scattering (Mini Dawn Wyatt) and refractive index (RI2000, Sopares or Wyatt Optilab Rex) detectors. The results were processed using Astra 6 software, using a $d n / d c$ value of 0.085 .

\subsubsection{Nuclear Magnetic Resonance (NMR) Spectroscopy}

The ${ }^{1} \mathrm{H}-{ }^{13} \mathrm{C}$ - and ${ }^{19} \mathrm{~F}-\mathrm{NMR}$ spectra were recorded on a Bruker AC 400 Spectrometer $(400 \mathrm{MHz}$ for ${ }^{1} \mathrm{H}, 100 \mathrm{MHz}$ for ${ }^{13} \mathrm{C}$ and $376 \mathrm{MHz}$ for ${ }^{19} \mathrm{~F}$ ) using $\mathrm{CDCl}_{3}$, THF- $d_{8}$ or acetone- $d_{6}$ as a solvent using the following experimental conditions for ${ }^{1} \mathrm{H}$ - (or ${ }^{13} \mathrm{C}$ - or ${ }^{19} \mathrm{~F}$ )-NMR spectra: flip angle $90^{\circ}$ (or $90^{\circ}$ or $30^{\circ}$ ); acquisition time $4.5 \mathrm{~s}$ ( or $0.3 \mathrm{~s}$ or $0.7 \mathrm{~s}$ ); pulse delay $2 \mathrm{~s}$ ( or 1 or $5 \mathrm{~s}$ ); number of scans 32 (or 8192 or 64), and; a pulse width of $12.5,9.5$ and $5.0 \mu$ s for ${ }^{1} \mathrm{H}-,{ }^{13} \mathrm{C}$ - and ${ }^{19} \mathrm{~F}-\mathrm{NMR}$, respectively. Coupling constants and chemical shifts are presented in Hertz $(\mathrm{Hz})$ and parts per million (ppm), respectively. ${ }^{1} \mathrm{H}$ decoupling was performed with waltz16. ${ }^{19} \mathrm{~F}$ decoupling was performed with nested loops using $0.5 \mathrm{~ms}$ and $1 \mathrm{~ms}$ chirped adiabatic pulses with $80 \mathrm{kHz}$ band with in order to desynchronize and minimize decoupling artifacts.

\section{Results and Discussion}

The performance of $\mathbf{3}$ as an OMRP mediator was assessed in the homopolymerization of VAc (Scheme 2a) and in the alternating copolymerization of VAc and MAF-TBE (Scheme 2b). 
(a)

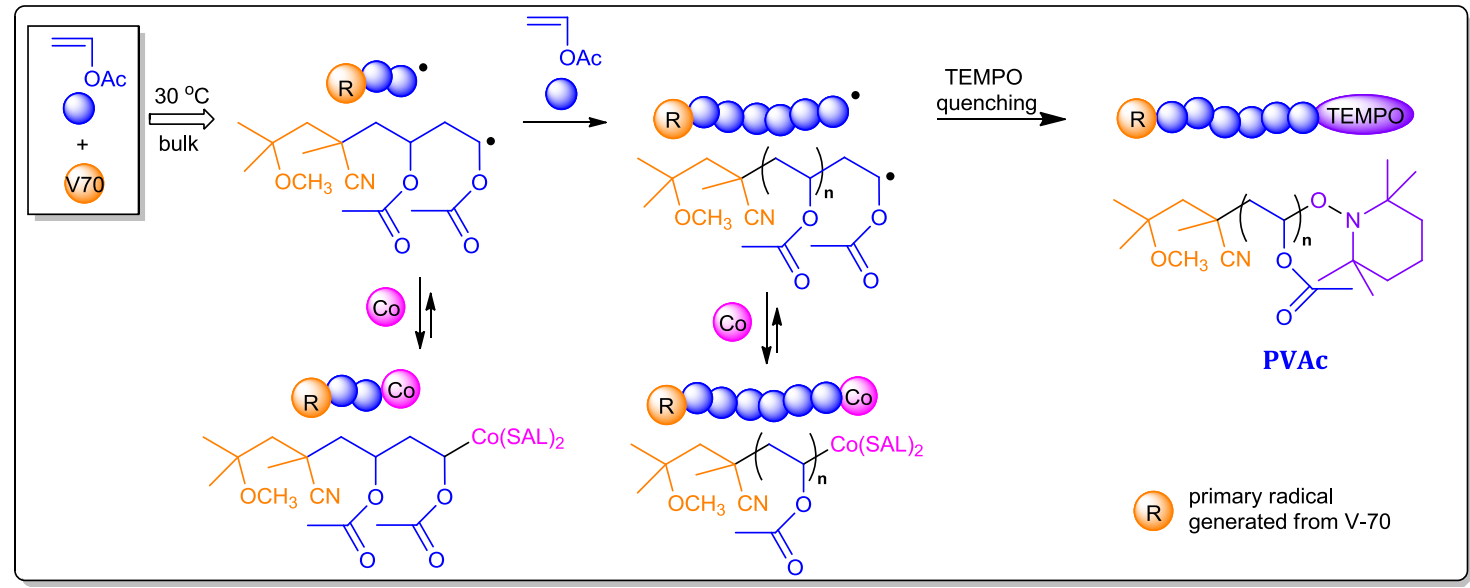

(b)

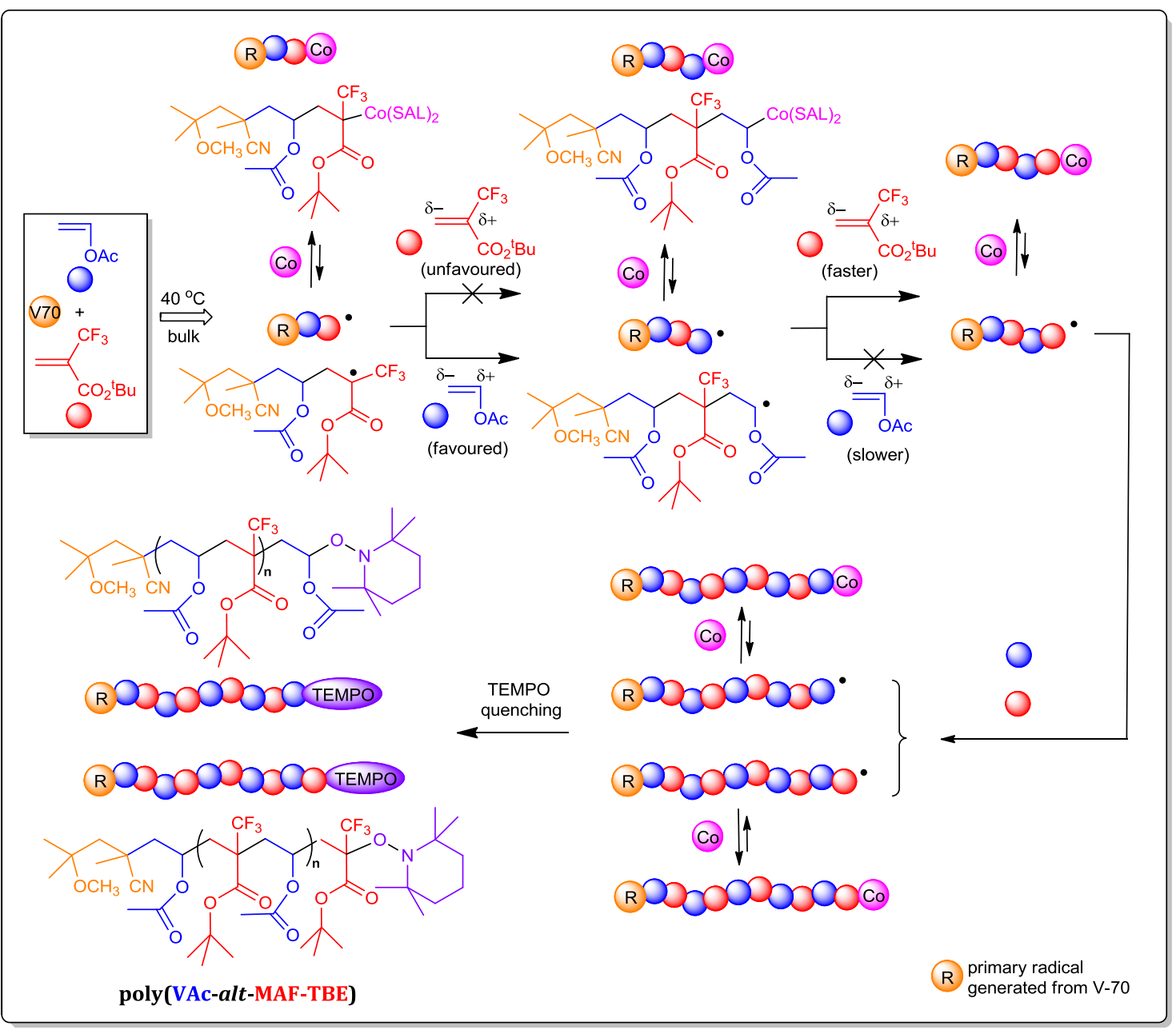

Scheme 2. Schematic representations of the cobalt-mediated radical polymerization (CMRP) of vinyl acetate (VAc) (a) and of VAc and tert-butyl 2-trifluoromethylacrylate (MAF-TBE) (b) mediated by 3. In (b), the first addition of the primary radical ( $R$ ) to VAc is arbitrarily assumed. The alternative $\mathrm{R}$ addition to MAF-TBE is also possible. 


\subsection{Homopolymerizations of VAc and MAF-TBE Mediated by 3}

Bulk homopolymerizations of VAc were carried out at $30^{\circ} \mathrm{C}$ using V-70 as initiator in the presence and absence of 3 . A V-70/3 ratio of 2 was used in the cobalt-mediated process, namely, conditions that allow a degenerate transfer controlling mechanism (excess radicals with respect to the putative organometallic dormant species). A first important observation is the absence of an induction time. This contrasts with the behavior reported for the same polymerization controlled by $\mathbf{1 a}[26,40], \mathbf{1 b}$ [27] and 1d [28], where essentially no polymer was formed until all the $\mathrm{Co}^{\mathrm{II}}$ complex was converted into the organometallic dormant species PVAc-Co ${ }^{\mathrm{III}}$, followed by controlled polymerization by degenerative transfer. On the other hand, the polymerization carried out in the presence of complex 2 [29] also exhibited no induction time, as in the present case. The conventional radical polymerization (no cobalt complex) ran slightly faster than the polymerization mediated by 3 , with apparent first-order $k_{p}$ values of $2.5 \times 10^{-5} \mathrm{~s}^{-1}$ (in the absence of complex) and $k_{p}=1.5 \times 10^{-5} \mathrm{~s}^{-1}$ (with 3), see Figure $1 \mathrm{a}$. Although the polymer dispersities $(\bigoplus)$ were similar at relatively low conversion (1.62 at $22 \%$ in the presence of 3 and 1.60 at 37\% in the conventional radical polymerization, Figure $1 \mathrm{~b}$ and Table S1), the dispersity increased to 1.99 at higher conversions for the PVAc obtained by conventional radical polymerization and only to 1.66 for that of the polymerization mediated by 3 . The polymerization carried out in the presence of 2, using the same VAc/V-70/Co ratio and temperature, gave a significantly lower apparent $k_{p}$ of $2.0 \times 10^{-6} \mathrm{~s}^{-1}$ [29]. These results suggest that 3 has the ability to reversibly interact with the growing radical chains, though less than $\mathbf{2}$ and much less than $\mathbf{1 a}, \mathbf{1 c}$ and $\mathbf{1 d}$, and that the trapping equilibrium is not sufficiently displaced in favor of the dormant species to ensure a good level of control. However, the low solubility of $\mathbf{3}$ in the VAc monomer may also contribute to this poor control. It is also relevant to note that there is no evidence of catalytic chain transfer (CCT), contrary to the polymerization mediated by 2 . Indeed, the isolated polymers had higher molar masses, according to the SEC analyses (Table S1), than predicted for a controlled polymerization. Attempts to obtain a homopolymer from MAF-TBE in the presence of $\mathbf{3}$ failed as expected, since this monomer does not homopolymerize under radical conditions $[35,36]$.
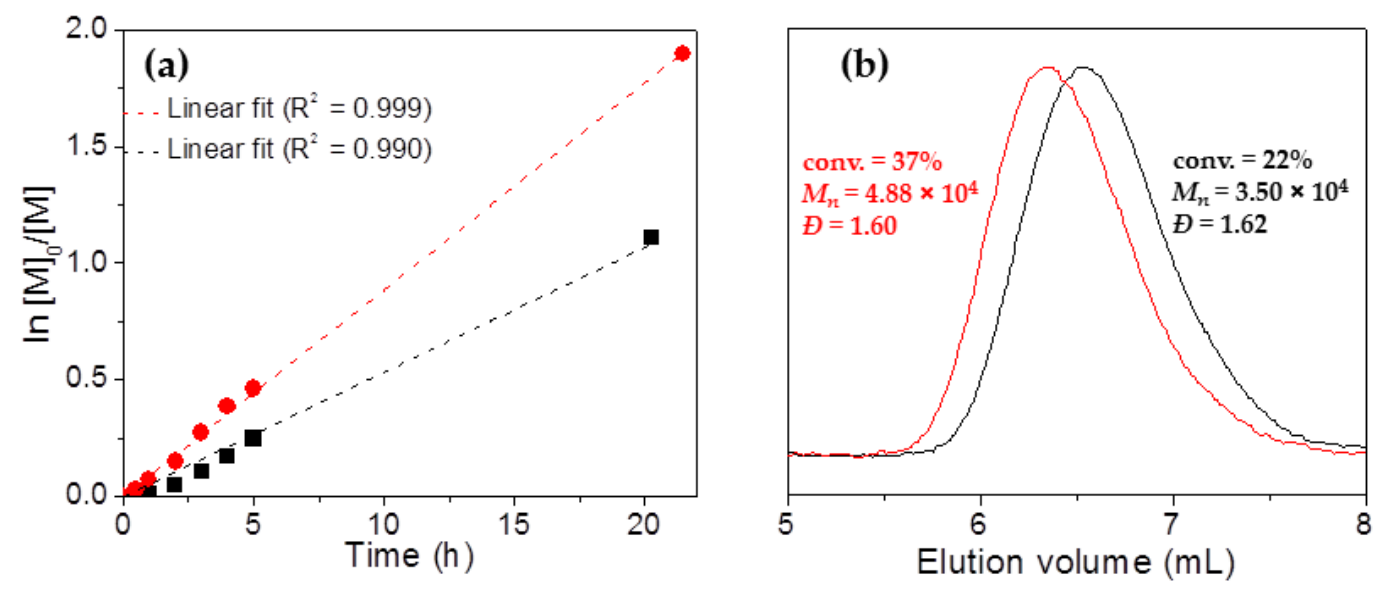

Figure 1. First order kinetic plot (a) and representative size exclusion chromatography (SEC) traces (b) for the radical polymerization of VAc mediated by 3 in bulk at $30{ }^{\circ} \mathrm{C}$ initiated by V-70 in the presence $\left\{[\mathrm{VAc}]_{0} /[\mathrm{V}-70]_{0} /[3]_{0}=500 / 2 / 1,(\bullet)\right\}$ and absence $\left\{[\mathrm{VAc}]_{0} /[\mathrm{V}-70]_{0}=500 / 2,(\bullet)\right\}$, of 3 .

\subsection{Copolymerization of VAc and MAF-TBE Mediated by 3}

Following this initial result with VAc, the bulk copolymerization of VAc and MAF-TBE (1:1 feed) mediated by 3 was investigated (Scheme 2b, Table S2). First, it should be pointed out that 3 exhibits greater solubility in the VAc/MAF-TBE mixture than in neat VAc (and even greater in neat MAF-TBE), although it was not fully soluble in the initial stages of the polymerization. The solutions became homogeneous at higher conversions as all the complex became incorporated in the propagating 
polymer chains. The copolymerization progress was monitored by ${ }^{1} \mathrm{H}-$ and ${ }^{19} \mathrm{~F}-\mathrm{NMR}$ spectroscopies to determine the VAc and MAF-TBE conversions, respectively (the stacked spectra are shown in Figures S1 and S2). As expected, since these monomers are known to copolymerize in an alternating manner $[34,35]$, equimolar conversions of VAc and MAF-TBE were recorded throughout the polymerization (Figure 2 and Table S2). The broad ${ }^{1} \mathrm{H}$ NMR signal centered at $5.20 \mathrm{ppm}$ (Figure S1) was assigned to the methine group of VAc in the VAc-MAF-TBE alternating dyad [35]. In contrast, the methine group in the PVAc homopolymer gives a signal at $4.80 \mathrm{ppm}$ [41].

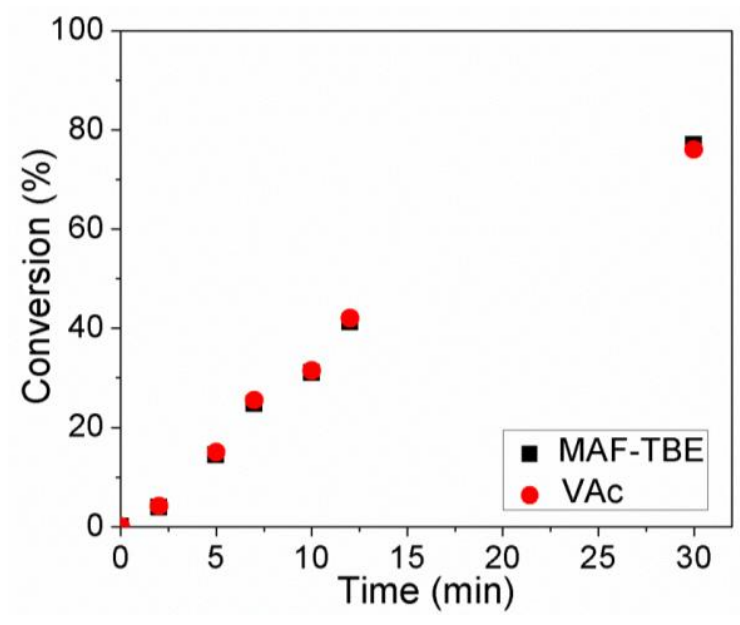

Figure 2. Conversion of VAc and MAF-TBE vs. time for the bulk copolymerization of VAc and MAF-TBE at $40{ }^{\circ} \mathrm{C}$ initiated by V-70 in the presence of $3\left\{[\mathrm{VAc}]_{0}+[\mathrm{MAF}-\mathrm{TBE}]_{0}\right\} /[\mathrm{V}-70]_{0} /[3]_{0}=537 / 3 / 1$, $[\mathrm{VAc}]_{0} /[\mathrm{MAF}-\mathrm{TBE}]_{0}=1 / 1$.

Confirmation of the alternating structure was supported by detailed ${ }^{1} \mathrm{H}-,{ }^{19} \mathrm{~F}$ - and ${ }^{13} \mathrm{C}-\mathrm{NMR}$ characterizations (Figures S3-S5), in excellent agreement with the previously published spectroscopic characterization of this polymer [34,35]. Notably, the ${ }^{1} \mathrm{H}-\mathrm{NMR}$ spectrum (Figure S3) shows the characteristic resonance of the VAc-CHOAc units in the VAc-MAF-TBE alternating dyad [34,35,42-45], which is significantly shifted from that of the same units in the homopolymer, and those of the $-\mathrm{C}\left(\mathrm{CH}_{3}\right)_{3}$ of MAF-TBE units [34,35]. The notable absence of -CHOAc signal corresponding to the PVAc homopolymer at $4.8 \mathrm{ppm}$ [41] is consistent with the exclusive formation of an alternating copolymer. The ${ }^{19} \mathrm{~F}-\mathrm{NMR}$ spectrum (Figure $\mathrm{S} 4$ ) reveals the characteristic signal of the $-\mathrm{CF}_{3}$ group in the MAF-TBE units at $-69 \mathrm{ppm}[46]$. The ${ }^{13} \mathrm{C}\left\{{ }^{19} \mathrm{~F}\right\}-\mathrm{NMR}$ spectrum (Figure S5) allows the full resonance assignment in accordance to the expected poly(VAc-alt-MAF-TBE) structure [35]. The resonance centered at $67.5 \mathrm{ppm}$ has a complex shape, probably because of the presence of different stereoisomers in the alternating MAF-TBE-VAc-MAF-TBE triads.

The first-order kinetic plot of this copolymerization (Figure 3) is linear, consistent with a constant radical concentration throughout the copolymerization. In addition, an induction period of about $1.5 \mathrm{~h}$ was observed, consistent with the higher initial solubility of $\mathbf{3}$ in the VAc/MAF-TBE mixture and confirming that 3 is indeed able to trap all radicals until the polymerization kicks off by degenerate transfer once all $\mathbf{3}$ is converted to the dormant alkylcobalt(III) complex. 


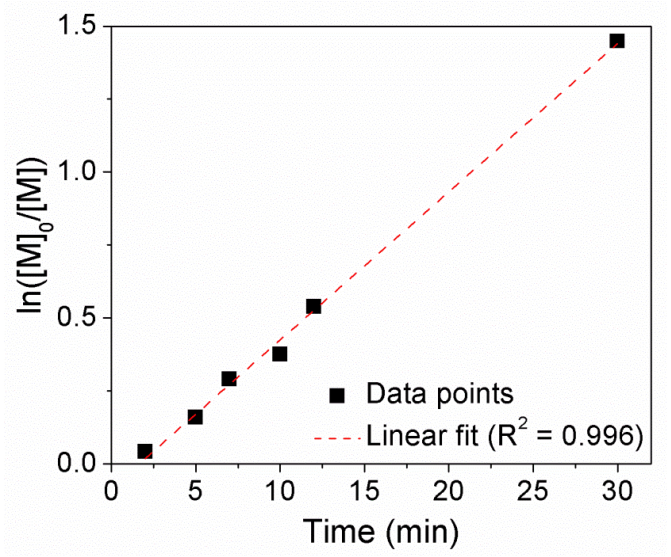

Figure 3. First order plot for the bulk copolymerization of VAc and MAF-TBE at $40{ }^{\circ} \mathrm{C}$ initiated by V-70 in the presence of $3\left\{[\mathrm{VAc}]_{0}+[\mathrm{MAF}-\mathrm{TBE}]_{0}\right\} /[\mathrm{V}-70]_{0} /[3]_{0}=537 / 3 / 1,[\mathrm{VAc}]_{0} /[\mathrm{MAF}-\mathrm{TBE}]_{0}=1 / 1$.

The SEC traces of this alternating copolymerization (Figure 4a) remained monomodal throughout the reaction, with an essentially linear evolution of the copolymer molar mass $\left(M_{n}\right)$ versus monomer conversion (Figure $4 \mathrm{~b}$ ) and dispersities that decreased as conversion increased. These are characteristic features of a controlled polymerization. However, the dispersity remained relatively high $(\boxplus=1.55-1.75)$ compared with that of the corresponding $\mathrm{Co}(\mathrm{acac})_{2}$-mediated copolymerization [35]. The initial ( $<20 \%$ monomer conversion) poorly controlled phase, indicated by the higher $Ð$ values is probably partially due to the incomplete solubility of $\mathbf{3}$ in the bulk monomer mixtures.
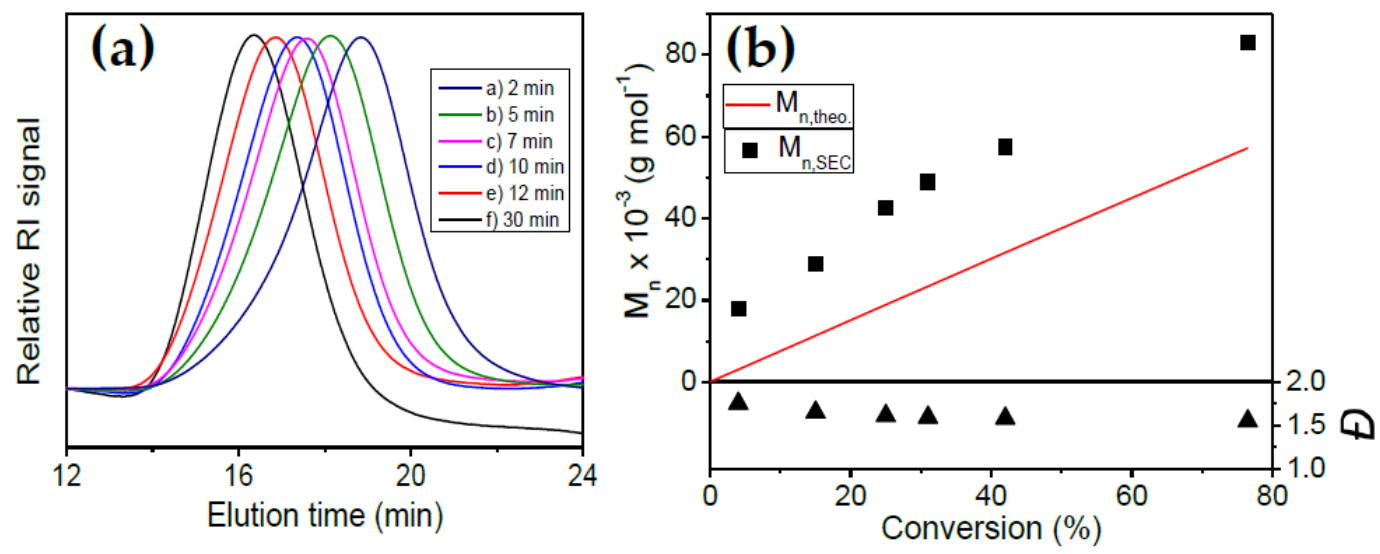

Figure 4. Evolutions of the SEC traces vs. elution time (a) and dependence of $M_{n}$ and $\emptyset$ vs. total monomer conversion (b) for the bulk copolymerization of VAc with MAF-TBE at $40{ }^{\circ} \mathrm{C}$ initiated by $\mathrm{V}-70$ in the presence of $3,\left\{[\mathrm{VAc}]_{0}+[\mathrm{MAF}-\mathrm{TBE}]_{0}\right\} /[\mathrm{V}-70]_{0} /[3]_{0}=537 / 3 / 1,[\mathrm{VAc}]_{0} /[\mathrm{MAF}-\mathrm{TBE}]_{0}=1 / 1$. The straight line in (b) represents the theoretical $M_{n}$, based on one chain per Co atom.

\section{Conclusions}

In conclusion, this study reports, for the first time, the action of bis(2-formylphenolato)cobalt(II) complex as an OMRP controlling agent. The moderating equilibrium is less in favor of the dormant species relative to species $\mathbf{1 a}, \mathbf{1} \mathbf{b}$ and $\mathbf{1 d}$, not allowing a sufficient level of control for the homopolymerization of VAc. This effect is similar to that recently reported for the 9-oxyphenalenone derivative (2) [29], which has a similar structure to complex 3. However, contrary to the VAc polymerization mediated by 2 , the one mediated by 3 shows no evidence of catalytic chain transfer to monomer, indicating that 3 not only makes homolytically weaker PVAc-Co ${ }^{\mathrm{III}}$ bonds in the dormant species relative to $\mathbf{1 a}$, but also has a lower aptitude to abstract a $\beta-\mathrm{H}$ atom from the growing 
radical PVAc chains. The OMRP testing of 3 was then extended to the alternating copolymerization of VAc and MAF-TBE, enabling a relatively well-controlled synthesis of a strictly alternating poly(VAc-alt-MAF-TBE) copolymer under degenerative transfer conditions. The moderately controlled behavior of this alternating copolymerization is suggested by the linear semilogarithmic plot, the linear $M_{n}$-conversion plot, and the acceptable $Ð$ values which decrease as the conversion increases. The alternating structure of the copolymer was confirmed by detailed microstructure analysis using NMR.

We have therefore extended the array of available $\mathrm{Co}^{\mathrm{II}}$ complexes based on a fully oxygen-based coordination sphere to the $\mathrm{Co}(\mathrm{SAL})_{2}$ complex 3 for OMRP applications. Although the initial results presented here show lower performance in the homopolymerization of VAc and alternating copolymerization of VAc and MAF-TBE relative to the acac complex 1a, because of less favorable trapping equilibria, the system has potential in the controlled radical polymerization of other LAMs such as fluorinated olefins and work along this direction is currently ongoing in our laboratories.

Supplementary Materials: The following are available online at www.mdpi.com/2073-4360/9/12/702/s1. Tables of data for bulk VAc homopolymerization and VAc/MAF-TBE alternating copolymerization, stacked plots of the evolution of the ${ }^{1} \mathrm{H}$ - and ${ }^{19} \mathrm{~F}-\mathrm{NMR}$ spectra for the copolymerization, and ${ }^{1} \mathrm{H}-,{ }^{19} \mathrm{~F}$ - and ${ }^{13} \mathrm{C}\left\{{ }^{19} \mathrm{~F}\right\}-\mathrm{NMR}$ spectra of the isolated poly(VAc-alt-MAF-TBE) copolymer.

Acknowledgments: The authors thank Tosoh F-Tech Company (Shunan, Japan) for providing MAF-TBE. Financial support from the French National Agency (ANR grant FLUPOL, No. ANR-14-CE07-0012-02) is greatly acknowledged. Christophe Detrembleur and Antoine Debuigne are Research Director and Research Associate by F.R.S.-FNRS, respectively, and thank the FNRS for financial support.

Author Contributions: Sanjib Banerjee, Ekaterina V. Bellan, Florence Gayet, Rinaldo Poli, Bruno Améduri, Vincent Ladmiral, Antoine Debuigne and Christophe Detrembleur conceived and designed the experiments; Sanjib Banerjee and Ekaterina V. Bellan performed the experiments, analyzed the data and wrote the paper which was edited and improved by all the co-authors.

Conflicts of Interest: The authors declare no conflict of interest. The founding sponsors had no role in the design of the study; in the collection, analyses, or interpretation of data; in the writing of the manuscript, and in the decision to publish the results.

\section{References}

1. Smith, D.W.; Iacono, S.T.; Iyer, S.S. Handbook of Fluoropolymer Science and Technology; Wiley: New York, NY, USA, 2014.

2. Ameduri, B.; Sawada, H. Fluorinated Polymers: From Fundamental to Practical Synthesis and Applications; Royal Society of Chemistry: Oxford, UK, 2016.

3. Riess, G. Micellization of block copolymers. Prog. Polym. Sci. 2003, 28, 1107-1170. [CrossRef]

4. Sun, H.; Kabb, C.P.; Sumerlin, B.S. Thermally-labile segmented hyperbranched copolymers: Using reversible-covalent chemistry to investigate the mechanism of self-condensing vinyl copolymerization. Chem. Sci. 2014, 5, 4646-4655. [CrossRef]

5. Sun, H.; Kabb, C.P.; Dai, Y.; Hill, M.R.; Ghiviriga, I.; Bapat, A.P.; Sumerlin, B.S. Macromolecular metamorphosis via stimulus-induced transformations of polymer architecture. Nat. Chem. 2017, 9, 817-823. [CrossRef] [PubMed]

6. Nicolas, J.; Guillaneuf, Y.; Lefay, C.; Bertin, D.; Gigmes, D.; Charleux, B. Nitroxide-mediated polymerization. Prog. Polym. Sci. 2013, 38, 63-235. [CrossRef]

7. Matyjaszewski, K. Atom Transfer Radical Polymerization (ATRP): Current Status and Future Perspectives. Macromolecules 2012, 45, 4015-4039. [CrossRef]

8. David, G.; Boyer, C.; Tonnar, J.; Améduri, B.; Lacroix-Desmazes, P.; Boutevin, B. Use of iodocompounds in radical polymerization. Chem. Rev. 2006, 106, 3936-3962. [CrossRef] [PubMed]

9. Lopez, G.; Thenappan, A.; Ameduri, B. Synthesis of Chlorotrifluoroethylene-Based Block Copolymers by Iodine Transfer Polymerization. ACS Macro Lett. 2015, 4, 16-20. [CrossRef]

10. Asandei, A.D. Photomediated Controlled Radical Polymerization and Block Copolymerization of Vinylidene Fluoride. Chem. Rev. 2016, 116, 2244-2274. [CrossRef] [PubMed] 
11. Taton, D.; Destarac, M.; Zard, S.Z. Macromolecular Design by Interchange of Xanthates (MADIX): Background, Design, Scope, and Applications. In Handbook of RAFT Polymerization; Barner-Kowollik, C., Ed.; Wiley-VCH: Weinheim, Germany, 2008; pp. 373-421.

12. Barner-Kowollik, C. Handbook of RAFT Polymerization; Wiley-VCH: Weinheim, Germany, 2008.

13. Boyer, C.; Bulmus, V.; Davis, T.P.; Ladmiral, V.; Liu, J.; Perrier, S. Bioapplications of RAFT Polymerization. Chem. Rev. 2009, 109, 5402-5436. [CrossRef] [PubMed]

14. Hill, M.R.; Carmean, R.N.; Sumerlin, B.S. Expanding the Scope of RAFT Polymerization: Recent Advances and New Horizons. Macromolecules 2015, 48, 5459-5469. [CrossRef]

15. Zetterlund, P.B.; Thickett, S.C.; Perrier, S.; Bourgeat-Lami, E.; Lansalot, M. Controlled/Living Radical Polymerization in Dispersed Systems: An Update. Chem. Rev. 2015, 115, 9745-9800. [CrossRef] [PubMed]

16. Poli, R. Relationship between one-electron transition metal reactivity and radical polymerization processes. Angew. Chem. Int. Ed. Engl. 2006, 45, 5058-5070. [CrossRef] [PubMed]

17. Hurtgen, M.; Detrembleur, C.; Jerome, C.; Debuigne, A. Insight into Organometallic-Mediated Radical Polymerization. Polym. Rev. 2011, 51, 188-213. [CrossRef]

18. Poli, R. Organometallic Mediated Radical Polymerization. In Polymer Science: A Comprehensive Reference; Matyjaszewski, K., Möller, M., Eds.; Elsevier BV: Amsterdam, The Netherlands, 2012; Volume 3, pp. 351-375.

19. Poli, R. New phenomena in organometallic-mediated radical polymerization (OMRP) and perspectives for control of less active monomers. Chem. Eur. J. 2015, 21, 6988-7001. [CrossRef] [PubMed]

20. Debuigne, A.; Jerome, C.; Detrembleur, C. Organometallic-mediated radical polymerization of 'less activated monomers': Fundamentals, challenges and opportunities. Polymer 2017, 115, 285-307. [CrossRef]

21. Detrembleur, C.; Debuigne, A.; Hurtgen, M.; Jerome, C.; Pinaud, J.; Fevre, M.; Coupillaud, P.; Vignolle, J.; Taton, D. Synthesis of 1-Vinyl-3-ethylimidazolium-Based Ionic Liquid (Co)polymers by Cobalt-Mediated Radical Polymerization. Macromolecules 2011, 44, 6397-6404. [CrossRef]

22. Patil, N.; Cordella, D.; Aqil, A.; Debuigne, A.; Admassie, S.; Jerome, C.; Detrembleur, C. Surfaceand Redox-Active Multifunctional Polyphenol-Derived Poly(ionic liquid)s: Controlled Synthesis and Characterization. Macromolecules 2016, 49, 7676-7691. [CrossRef]

23. Debuigne, A.; Morin, A.N.; Kermagoret, A.; Piette, Y.; Detrembleur, C.; Jérôme, C.; Poli, R. Key Role of Intramolecular Metal Chelation and Hydrogen Bonding in the Cobalt-Mediated Radical Polymerization of N-Vinyl amides. Chem. Eur. J. 2012, 18, 12834-12844. [CrossRef] [PubMed]

24. Debuigne, A.; Poli, R.; Jérôme, C.; Jérome, R.; Detrembleur, C. Overview of cobalt-mediated radical polymerization: Roots, state of the art and future prospects. Prog. Polym. Sci. 2009, 34, 211-239. [CrossRef]

25. Wayland, B.B.; Poszmik, G.; Mukerjee, S. Living radical polymerization of acrylates by organocobalt porphyrin complexes. J. Am. Chem. Soc. 1994, 116, 7943-7944. [CrossRef]

26. Debuigne, A.; Caille, J.R.; Jérôme, R. Highly efficient cobalt-mediated radical polymerization of vinyl acetate. Angew. Chem. Int. Ed. Engl. 2005, 44, 1101-1104. [CrossRef] [PubMed]

27. Kaneyoshi, H.; Matyjaszewski, K. Radical (Co)polymerization of vinyl chloroacetate and N-vinylpyrrolidone mediated by bis(acetylacetonate)cobalt derivatives. Macromolecules 2006, 39, 2757-2763. [CrossRef]

28. Santhosh Kumar, K.S.; Gnanou, Y.; Champouret, Y.; Daran, J.-C.; Poli, R. Radical Polymerization of Vinyl Acetate with Bis(tetramethylheptadionato)cobalt(II): The Cohabitation of Three Different Mechanisms. Chem. Eur. J. 2009, 15, 4874-4885. [CrossRef] [PubMed]

29. Bellan, E.V.; Thevenin, L.; Gayet, F.; Fliedel, C.; Poli, R. Catalyzed Chain Transfer in Vinyl Acetate Polymerization mediated by 9-Oxyphenalenone Cobalt(II) complexes. ACS Macro Lett. 2017, 6, 959-962. [CrossRef]

30. Améduri, B. Controlled Radical (Co)polymerization of Fluoromonomers. Macromolecules 2010, 43, 10163-10184. [CrossRef]

31. Demarteau, J.; Ameduri, B.; Ladmiral, V.; Mees, M.A.; Hoogenboom, R.; Debuigne, A.; Detrembleur, C. Controlled Synthesis of Fluorinated Copolymers via Cobalt-Mediated Radical Copolymerization of Perfluorohexylethylene and Vinyl Acetate. Macromolecules 2017, 50, 3750-3760. [CrossRef]

32. Tyson, G.N.; Adams, S.C. The configuration of some cupric, nickelous and cobaltous complexes by means of magnetic measurements. J. Am. Chem. Soc. 1940, 62, 1228-1229. [CrossRef]

33. Cotton, F.A.; Holm, R.H. Magnetic investigations of spin-free cobaltous complexes 3. On the existence of planar complexes. J. Am. Chem. Soc. 1960, 82, 2979-2983. [CrossRef] 
34. Banerjee, S.; Domenichelli, I.; Ameduri, B. Nitroxide-Mediated Alternating Copolymerization of Vinyl Acetate with tert-Butyl-2-trifluoromethacrylate Using a SG1-Based Alkoxyamine. ACS Macro Lett. 2016, 5, 1232-1236. [CrossRef]

35. Banerjee, S.; Ladmiral, V.; Debuigne, A.; Detrembleur, C.; Rahaman, S.M.W.; Poli, R.; Améduri, B. Organometallic-Mediated Alternating Radical Copolymerization of tert-Butyl-2-trifluoromethacrylate with Vinyl Acetate and Synthesis of Block Copolymers Thereof. Macromol. Rapid Commun. 2017, 38, 1700203. [CrossRef] [PubMed]

36. Patil, Y.; Ameduri, B. Advances in the (Co)polymerization of Alkyl 2-Trifluoromethacrylates and 2-(Trifluoromethyl)acrylic Acid. Prog. Polym. Sci. 2013, 38, 703-739. [CrossRef]

37. Tillet, G.; Boutevin, B.; Ameduri, B. Chemical reactions of polymer crosslinking and post-crosslinking at room and medium temperature. Prog. Polym. Sci. 2010, 36, 191-217. [CrossRef]

38. Banerjee, S.; Wehbi, M.; Manseri, A.; Mehdi, A.; Alaaeddine, A.; Hachem, A.; Ameduri, B. Poly(vinylidene fluoride) Containing Phosphonic Acid as Anticorrosion Coating for Steel. ACS Appl. Mater. Interfaces 2017, 9, 6433-6443. [CrossRef] [PubMed]

39. Soulestin, T.; Dos Santos Filho, P.M.; Ladmiral, V.; Lannuzel, T.; Domingues Dos Santos, F.; Ameduri, B. Ferroelectric fluorinated copolymers with improved adhesion properties. Polym. Chem. 2017, 8, 1017-1027. [CrossRef]

40. Maria, S.; Kaneyoshi, H.; Matyjaszewski, K.; Poli, R. Effect of Electron Donors on the Radical Polymerization of Vinyl Acetate Mediated by Co(acac)2: Degenerative transfer versus reversible homolytic cleavage of an organocobalt(III) complex. Chem. Eur. J. 2007, 13, 2480-2492. [CrossRef] [PubMed]

41. Debuigne, A.; Champouret, Y.; Jérôme, R.; Poli, R.; Detrembleur, C. Mechanistic Insights into Cobalt Mediated Radical Polymerization (CMRP) of Vinyl Acetate via Cobalt(III) Adducts as Initiators. Chem. Eur. J. 2008, 14, 4046-4059. [CrossRef] [PubMed]

42. Kharas, G.; Kohn, D.H. Characterization of copolymers of vinyl acetate with ethyl $\alpha$-cyanocinnamate. J. Polym. Sci. Part A Polym. Chem. 1984, 22, 577-582. [CrossRef]

43. Kharas, G.; Kohn, D.H. Copolymerization of vinyl acetate with benzylidenemalononitrile. J. Polym. Sci. Part A Polym. Chem. 1984, 22, 583-588. [CrossRef]

44. Kharas, G.B.; Barbarawi, H.A.; Crawford, A.L.; Dotson-Newman, O.I.; Dukarevich, I.J.; Ekram, A.; Galzin, N.A.; Ghattas, R.M.; Hoang, J.M.; Hyland, L.A.; et al. Novel co-polymers of vinyl acetate and halogen ring-substituted methyl 2-cyano-3-phenyl-2-propenoates. Des. Monomers Polym. 2005, 8, 309-317. [CrossRef]

45. Kochi, T.; Nakamura, A.; Ida, H.; Nozaki, K. Alternating Copolymerization of Vinyl Acetate with Carbon Monoxide. J. Am. Chem. Soc. 2007, 129, 7770-7771. [CrossRef] [PubMed]

46. Patil, Y.; Améduri, B. First RAFT/MADIX radical copolymerization of tert-butyl 2-trifluoromethacrylate with vinylidene fluoride controlled by xanthate. Polym. Chem. 2013, 4, 2783-2799. [CrossRef] 